\title{
Intramuscular lipoma of the tongue: Report of a case complicated with
}

\section{diffuse lipomatosis}

Tomofumi Naruse ${ }^{\mathrm{a}}$, Souichi Yanamoto ${ }^{\mathrm{a},{ }^{*}}$, Toshihiro Kawano ${ }^{\mathrm{a}}$, Izumi Yoshitomi ${ }^{\mathrm{a}}$, Shin-ichi Yamada $^{\mathrm{a}}$, Goro Kawasaki ${ }^{\mathrm{a}}$, Shuichi Fujita ${ }^{\mathrm{b}}$, Tohru Ikeda ${ }^{\mathrm{b}}$, Masahiro Umeda ${ }^{\mathrm{a}}$

${ }^{\mathrm{a} D}$ Department of Clinical Oral Oncology, Unit of Translational Medicine, Course of Medical and Dental Sciences, Nagasaki University Graduate School of Biomedical Sciences, 1-7-1

Sakamoto, Nagasaki 852-8588, Japan

${ }^{\mathrm{b}}$ Department of Oral Pathology and Bone Metabolism, Unit of Translational Medicine, Course of Medical and Dental Sciences, Nagasaki University Graduate School of Biomedical Sciences, 1-7-1 Sakamoto, Nagasaki 852-8588, Japan

Corresponding author. Tel.: +81 95819 7698; fax: +8195 8197700

E-mail address: syana@nagasaki-u.ac.jp (S. Yanamoto). 


\section{ABSTRACT}

Intramuscular lipoma (IML) is an uncommon tumor in the oral cavity, and characterized by infiltrating adipose tissue and muscle atrophy. Although Oral IMLs are almost always solitary, we reported a rare case of IML of the tongue complicated with diffuse lipomatosis of the forearm. A 58-year-old woman was referred to our department with a painless swelling of the left tongue that had been present for 6 months. Clinical examination revealed a $35 \times 30 \times$ 20-mm well-defined, elastic soft mass in the anterior left region of the tongue border. The lesion was removed under general anesthesia via the left margin of the tongue. No signs of recurrence have been observed 15 months after surgery. In immunohistochemical analysis, the proliferative activity in our case was higher than other lipomas.

Keywords: intramuscular lipoma; tongue; diffuse lipomatosis 


\section{Introduction}

Intramuscular lipoma (IML) is a slow-growing painless lesion usually found in the great muscles of the extremities of adult males, and is characterized by infiltrating adipose tissue and muscle atrophy [1]. It occurs in less than $2 \%$ of all lipomas [2] and is extremely rare in oral and maxillofacial regions [3, 4]. Since a local recurrence rate ranging from $19 \%$ to $62.5 \%$ after surgical excision has been reported in some literature [2, 5], wide local excision and appropriate clinical monitoring of patients are mandatory [5].

Oral IMLs are almost always solitary [6]. We here report a case of IML of the tongue complicated with diffuse lipomatosis of the forearm. To the best of our knowledge, only 2 other such cases of lipoma have been reported [7, 8]; however, these two cases were classical lipomas, not IMLs.

\section{Case report}

A 58-year-old woman was referred to our department in July 2010 with a painless swelling of the left tongue that had been present for 6 months. Clinical examination revealed a $35 \times 30 \times 20$-mm well-defined, elastic soft mass in the anterior left region of the tongue border (Fig. 1). The overlying mucosa was normal in color and texture with no ulceration or 
inflammation. The patient had tongue dysmotility and dysarthria, but didn’t have dysgeusia and sensory changes. Magnetic resonance imaging (MRI) was performed for differential diagnosis and preoperative evaluation of the mass. T1-weighted images revealed well-circumscribed high signal intensity (Fig. 2A), while fat-saturation T1-weighted images revealed well-circumscribed low signal intensity in the same region (Fig. 2B). Multiple superficial masses were present throughout her upper limbs (Fig. 3A). The patient's past medical history was diffuse lipomatosis of the right forearm eight years previously, and the histological diagnosis of the biopsy was angiolipoma (Fig. 3B). These lesions were followed up without treatment. The other medical history was unremarkable. The patient was clinically diagnosed as a tongue lipoma complicated with diffuse lipomatosis of the upper limb.

The lesion was removed under general anesthesia via the left margin of the tongue. Although removal was easy, some parts of the lesion were firmly attached to the muscles of the tongue. We therefore removed these with surrounding tissue. The gross appearance of the specimen was a yellowish fatty mass with unclear encapsulation. The cut surface of the removed specimen revealed foliate nodes with scattered muscle tissue (Fig. 4). Histological examination revealed that the specimen was covered with an incomplete fibrous capsule partially containing skeletal muscle fibers (Fig. 5A). The tumor was composed of mature 
adipose cells including scattered bundles of skeletal muscle fibers. There were no lipoblasts or cells with atypical nuclei (Fig. 5B). On the basis of these findings, the lesion was histopathologically diagnosed as an IML. No signs of recurrence, dysmotility, dysarthria and lingual nerve palsysis have been observed 15 months after surgery.

\section{Discussion}

ML is a rare variant of lipoma first defined by Paget et al. in 1853. The most common site is the skeletal muscles of both upper and lower extremities [1]. Fletcher et al. reported that the incidence of IML in general was 45 out of 2473 lipomas (1.8\%) [2]. Although lipomas usually occur sporadically, some are associated with several inherited disorders, including multiple lipomatosis, Gardner syndrome, Cowden syndrome, and Madelung disease [9]. Our present case could not be associated with any familial diseases. The relationship between IML and multiple subcutaneous angiolipoma was unknown.

To the best of our knowledge, 55 cases of IML of the oral cavity have been reported in the English literature [3, 4, 10-29]. The tongue is the most common site of involvement and accounts for about $40 \%$ of all cases, followed by the cheek and submandibular region. The mean age of all patients in the previous studies was 47.8 years, compared with 57.6 years in 
the tongue cases. Moreover, the mean tumor size of all cases was $4.3 \mathrm{~cm}$, compared with 2.9 $\mathrm{cm}$ in the tongue cases. The reason for finding many cases of small tumors on the tongue is that they are detected relatively early because they tend to protrude from the lingual mucosa and patients notice symptoms easily. In contrast, IML in the extremities is often detected incidentally on routine X-ray examination because they occur as deep-seated masses that are usually painless [1].

Clinically, oral IML presents as a well-circumscribed and painless solitary submucosal swelling, but on rare occasions, the infiltration is so extensive that it can cause muscle dysfunction or sensory changes due to pressure on nerve trunks; pain is rarely severe [16, 20]. In cases of IML of tongue, tongue dysmotility and dyssarthria is mainly due to the IML's infiltrative property has not been reported [3, 4, 10-29]. In our case, the reason of them is probably due to the relatively larger size of the lesion.

The differential diagnosis of IML includes well-differentiated liposarcoma, which often includes many areas of lipomatous tissue. In our case, there were no areas of lipoblastic proliferation, cellular pleomorphism or mitoses suggesting liposarcoma. MRI can be useful for diagnosis. On MRI, IML reveals a single mass with a homogeneous internal structure, while well-differentiated liposarcoma reveals a multinodular mass with an inhomogeneous 
internal structure and thick septa [30, 31]; however, as it was reported that IML is sometimes an inhomogeneous mass with an infiltrative margin, it was difficult to distinguish only by imaging studies. ${ }^{24}$ In our case, a preoperative diagnosis of lipoma could be suggested from MRI findings because of it revealed a single mass with a homogeneous internal structure and clear margin. In general, treatment of IML is based on its complete surgical excision.

The local recurrence rate of IML has been reported to range from 19 to $62.5 \%$, and the time between surgery and lesion reappearance has been reported to be an average of 6 to 7.5 years [2, 32]. No malignant changes have been reported for recurrent IMLs [32]. This high recurrence rate is related to the difficulty of achieving radical surgical excision, because IMLs are often more deeply situated, not encapsulated, and have an infiltrative growth pattern. Just two cases in the oral cavity have been previously reported $[12,18]$. No recurrent cases in the tongue have been reported. In our case, although some parts of the lesion were firmly attached to the muscles of the tongue, we removed it together with surrounding muscle tissue. Postoperative pathological examination revealed that the lesion was completely removed.

In conclusion, no signs of recurrence have been observed 15 months after surgery in our case; however, long-term follow-up with imaging examination is important because of active proliferative behavior, which was determined by the immunohistochemical results. 


\section{References}

[1] Enzenger FM. Soft tissue tumors. St Louis: Mosby; 1983, p. 223-227

[2] Fletcher CD, Martin-Bates E. Intramuscular and intermuscular lipoma. neglected diagnoses. Histopathology 1988; 12: 275-87.

[3] Furlong MA, Fanburg-Smith JC, Childers EL. Lipoma of the oral and maxillofacial region. Site and subclassification of 125 cases. Oral Surg Oral Med Oral Pathol Oral Radiol Endod 2004; 98: 441-50.

[4] Fregnani ER, Pires FR, Falzoni R, Lopes MA, Vargas PA. Lipomas of the oral cavity: clinical findings, histological classification and proliferative activity of 46 cases. Int J Oral Maxillofac Surg 2003; 32:49-53.

[5] Dione PG, Seemayer TA. Infiltrating lipomas and angiolipomas revised. Cancer 1974; 33: 732-8.

[6] Manor E, Sion-Vardy N, Joshua BZ, Bodner L. Oral lipoma: analysis of 58 new cases and review of the literature. Ann Diagn Pathol 2011; 15: 257-61.

[7] Weniq BM. Lipomas of the larynx and hypopharynx: a review of the literature with the addition of three new cases. J Laryngol Otol 1995; 109: 353-7.

[8] Durr ML, Agrawal N, Saunders JR, Ha PK. Laryngeal lipoma associated with diffuse lipomatosis: case report and literature review. Ear Nose Throat J 2010; 89: 34-7.

[9] EI-Monem MH, Gaafar AH, Maqdy EA. Lipomas of the head and neck: presentation variability and diagnostic work-up. J Laryngol Otol 2006; 120: 47-55. 
[10] Epivatianos A, Markopoulos AK, Papanayotou P. Benign tumors of adipose tissue of the oral cavity: a clinicopathologic study of 13 cases. J Oral Maxillofac Surg 2000; 58: 1113-7.

[11] Bennhoff DF, Wood JW. Infiltrating lipoma of the head and neck. Laryngoscope 1978; 88: 839-48.

[12] Scherl MP, Som PM, Biller HF, Shah K. Recurrent infiltrating lipoma of the head and neck: case report and literature review. Arch Otolaryngol Head Neck Surg 1986; 112: 1210-2. [13] Garavaglia J, Gnepp DR. Intramuscular (infiltrating) lipoma of the tongue. Oral surg Oral Med Oral Pathol 1987; 63: 348-50.

[14] Takeda Y. Intramuscular lipoma of the tongue:of the tongue: report of a rare case. Ann Dent 1989; 48: 22-4.

[15] Shirasuna K, Saka M, Watatani K, Kogo M, Matsuya T. Intramuscular lipoma of the tongue. Int J Oral Maxillofac Surg 1989; 18: 68-9.

[16] Pelissier A, Sawaf M.H, Shabana AH. Infiltrating (intramuscular) benign lipoma of the head and neck. J Oral Maxillofac Surg 1991; 49: 1231-6.

[17] Ayasaka N, Chino T Jr, Chino T, Antoh M, Kawakami T. Infiltrating lipoma of the mental region: Report of a case. Br J Oral Maxillofac Surg 1993; 31: 388-90.

[18] Lacey MS, Craig I. Infiltrating lipoma of the face. Ann Plast Surg 1995; 35: 307-9.

[19] Bataineh AB, Mansour MJ, Abalkhail A. Oral infiltrating lipomas. Br J Oral Maxillofac Surg 1996; 34: 520-3.

[20] Piattelli A, Fioroni M, Rubini C. Intramuscular lipoma of the cheek: a case report. J Oral Maxillofac Surg 2000; 58: 817-9. 
[21] Keskin G, Ustundag E, Ercin C. Multiple infiltrating lipomas of the tongue. J Laryngol Otol 2002; 116: 395-7.

[22] Uemura T, Suse T, Yokoyama T, Mitsukawa N, Yoshikawa A. Intramuscular benign lipoma of the temporalis muscle. Scand J Plast Reconstr Surg Hand Surg 2002; 36: 231-4. [23] Ban M, Kitajima Y. Intramuscular lipoma with in the temporal muscle. Int J Dermatol 2002; 41: 689-90.

[24] Salvatore C, Antonio B, Del Vecchino W, Lanza A, Tartaro G, Giuseppe C. Giant infiltrating lipoma of the face. CT and MR imaging findings. AJNR Am J Neuroradiol 2003; 24: 283-6.

[25] Scolozzi P, Lombardi T, Maire G, Pedeutour F, Richter M. Infiltrating intramuscular lipoma of the temporal muscle: a case report with molecular cytogenetic analysis. Oral Oncol 2003; 39: 316-22.

[26] Bandeca MC, de Padua JM, Nadalin MR, Ozorio JE, Silva-Sousa YT, da Cruz Perez DE. Oral soft tissue lipomas: a case series. J Can Dent Assoc 2007; 73: 431-4.

[27] Hashitani S, Toyohara Y, Sakurai K, Urade M. Intramuscular lipoma of the cheek: report of two cases. Oral Sci Int 2008; 5: 69-71.

[28] de Freitas MA, Freitas VS, de Lima AA, Pereira FB Jr, dos Santos JN. Intraoral lipomas: A study of 26 cases in a Brazilian populatin. Quintessence Int 2009; 40: 79-85. [29] Colella G, Biondi P, Caltabiano R, Vecchio GM, Amico P, Magro G. Giant intramuscular lipoma of the tongue: a case report and literature review. Cases J 2009; 22: 7906. 
[30] Matsumoto K, Hukuda S, Ishizawa M, Chano T, Okabe H. MRI findings in intramuscular lipomas. Skeketal Radiol 1999; 28: 145-52.

[31] Ohguri T, Aoki T, Hisaoka M, Watanabe H, Nakamura K, Hashimoto H, et al. Differential diagnosis of benign peripheral lipoma from well-differentiated liposarcoma on MR imaging: is comparison of margins and internal characteristics useful? AJR Am J Roentgenol 2003; 180: 1689-94.

[32] Dionne GP, Seemayer TA. Infiltrating lipoma and angiolipomas revisited. Cancer 1974; 33: 732-8. 


\section{Figure legends}

Figure 1. Photograph showing a $35 \times 30 \times 20 \mathrm{~mm}$, well-defined, elastic soft mass in the tongue.

Figure 2. Axial magnetic resonance images of the lesion. (A) T1-weighted image revealing a well-circumscribed high signal density in the left tongue. (B) Fat-saturation T1-weighted images revealing well-circumscribed low signal density.

Figure 3. (A) Multiple superficial masses were present throughout her upper limbs. (B) Biopsy from the forearm. The tumor was mainly composed of mature fat cells. Foci of fibrous connective tissue were included accompanied with many blood capillaries (H\&E staining $\times 10)$.

Figure 4. Photograph of removed intramuscular lipoma. The tumor was a yellowish fatty mass with unclear encapsulation. The cut surface of the removed tumor revealed foliate nodes with scattered red tissue. 
Figure 5. (A) Photomicrograph revealed that the tumor was covered with an unclear capsule containing partially skeletal muscle fibers $(H \& E$ staining $\times 25)$. (B) Bundles of skeletal muscle fibers were apparent within the proliferation of adipose cells. No lipoblasts were present and there was a complete absence of cellular atypia (H\&E staining $\times 50)$. 
Figure 1.

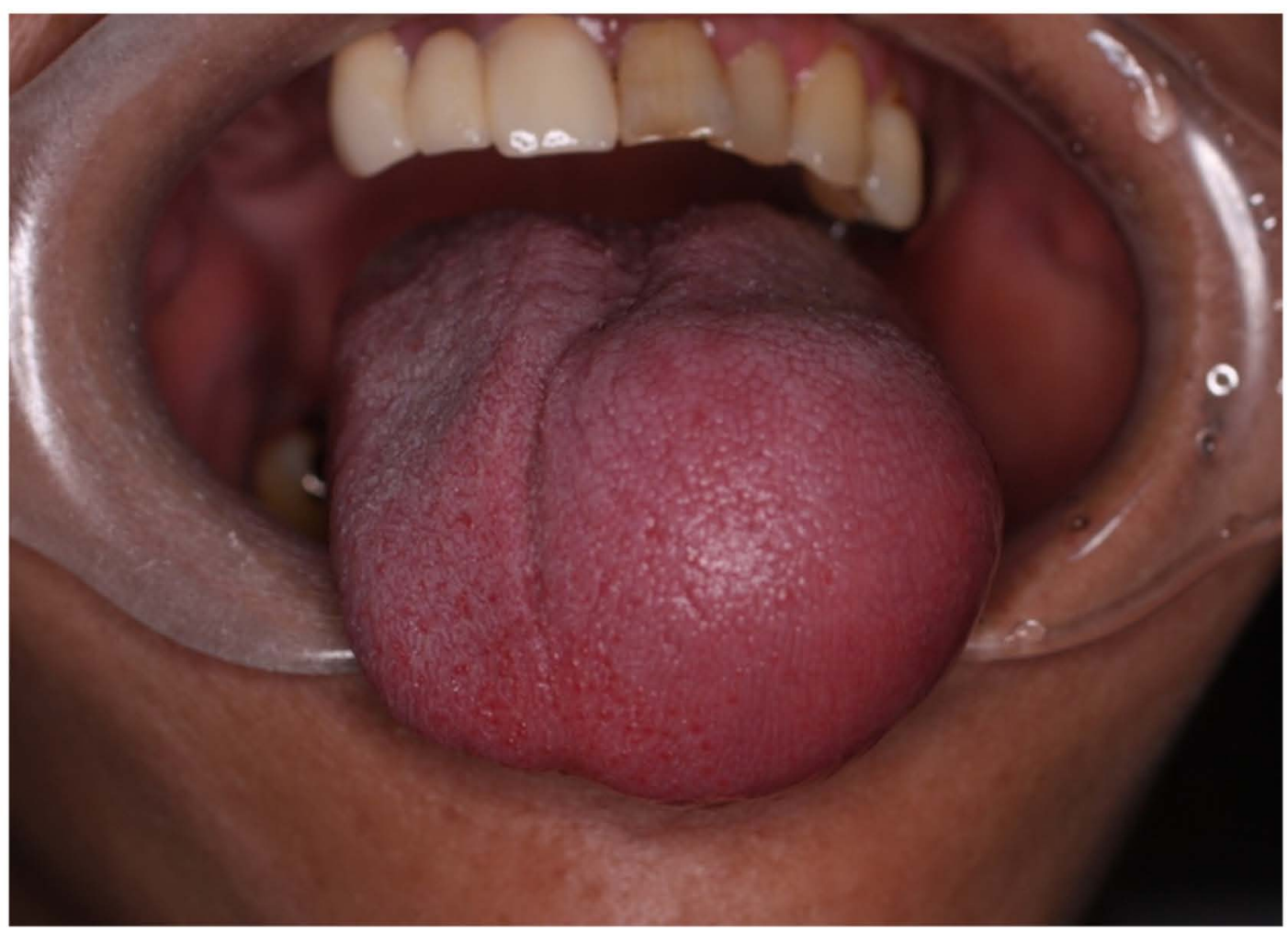


Figure 2.
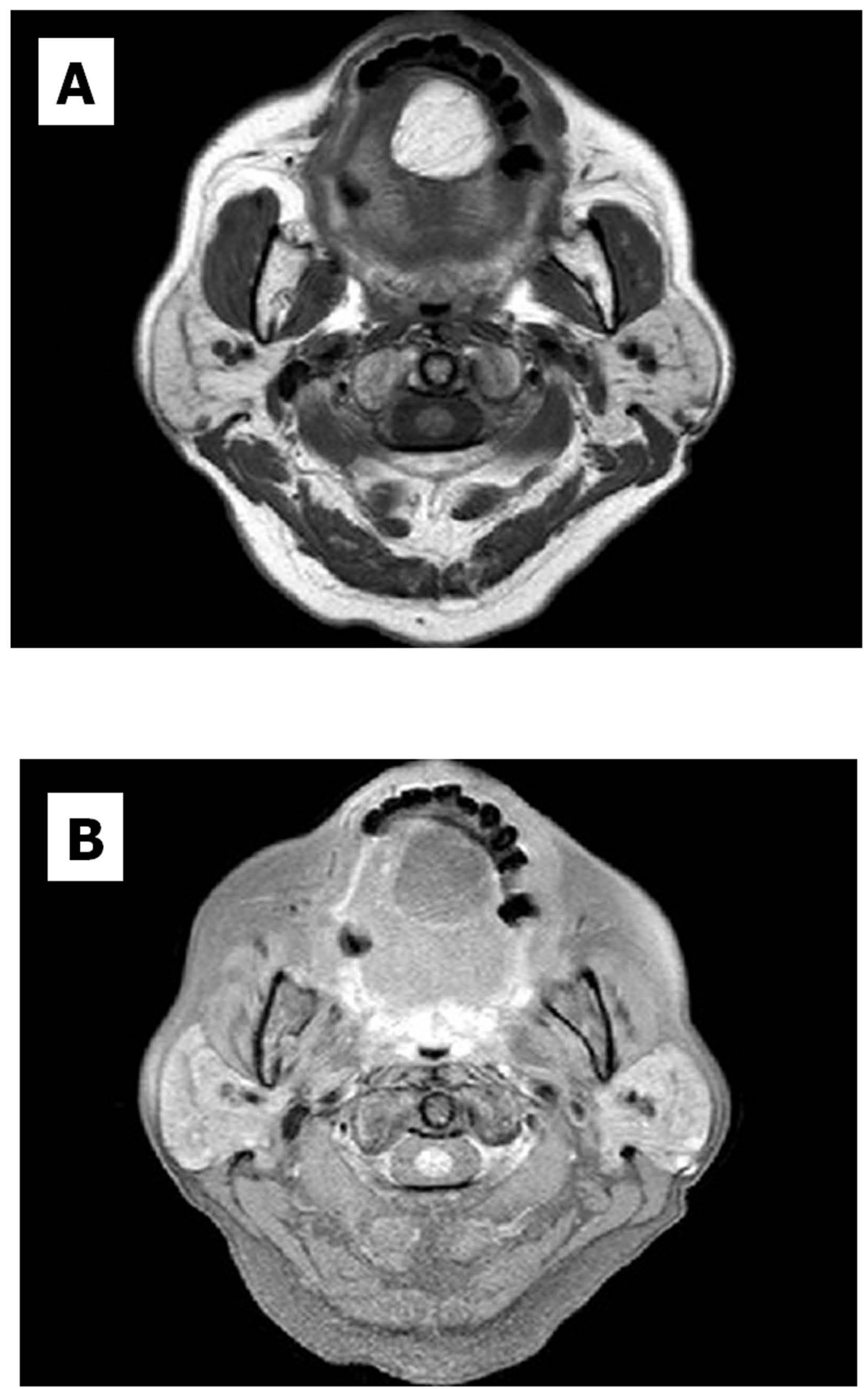
Figure 3.

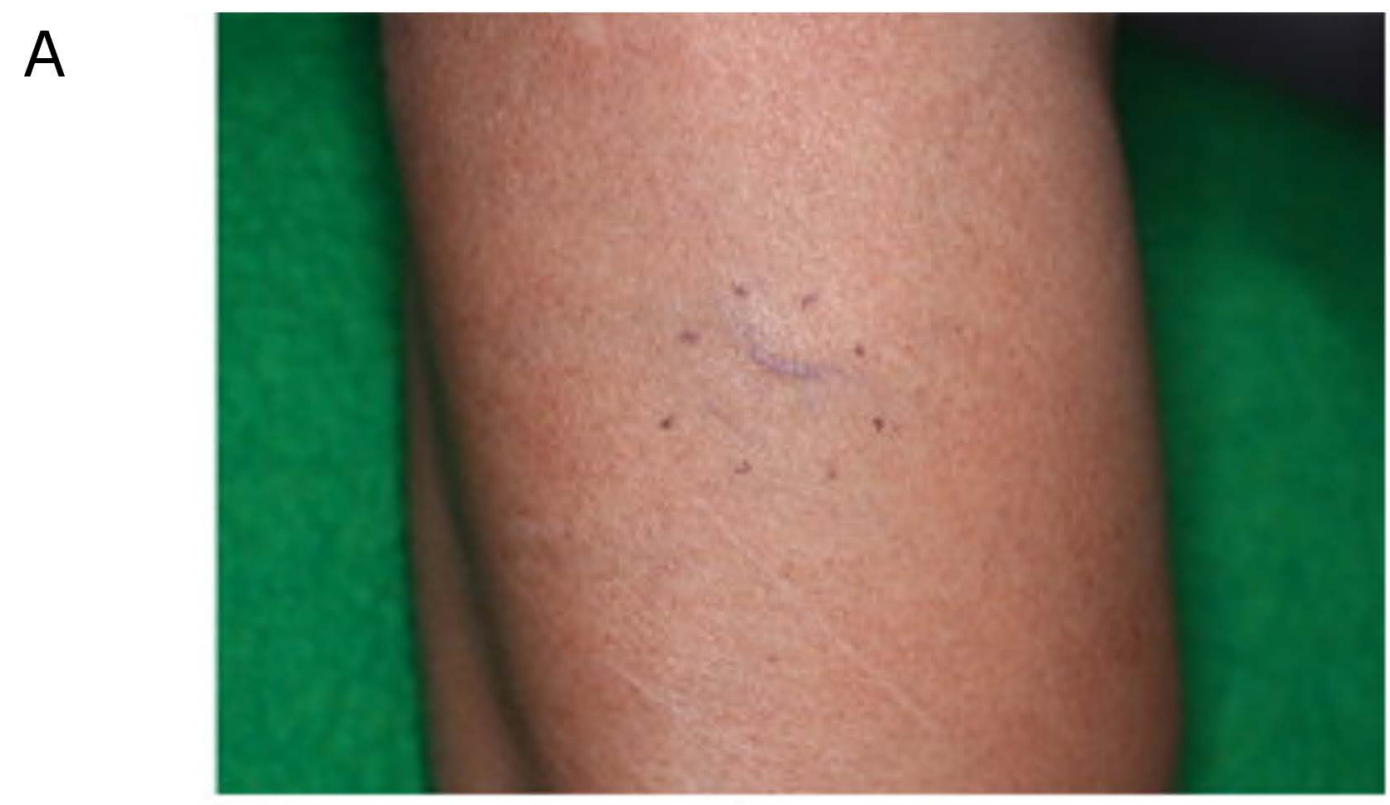

B

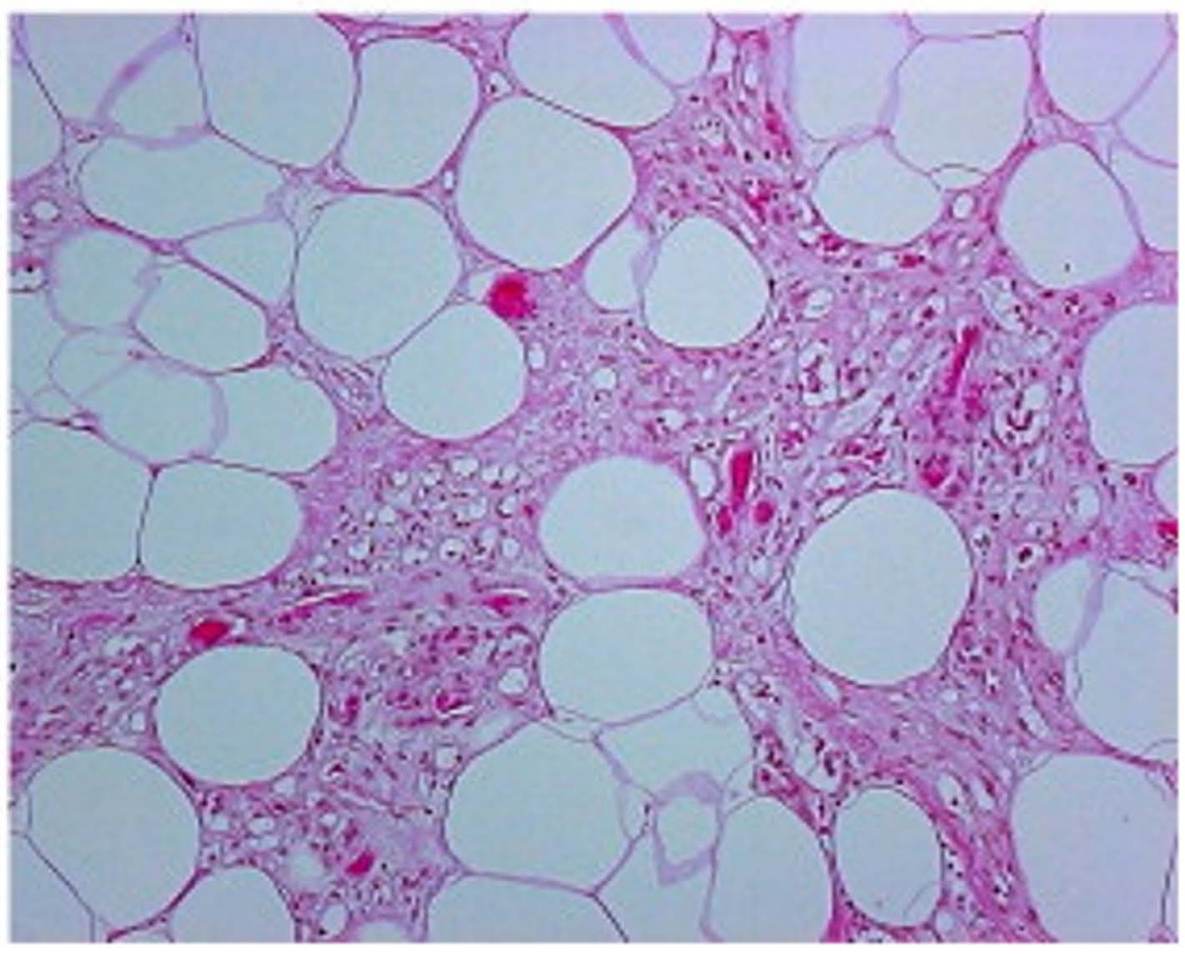


Figure 4.

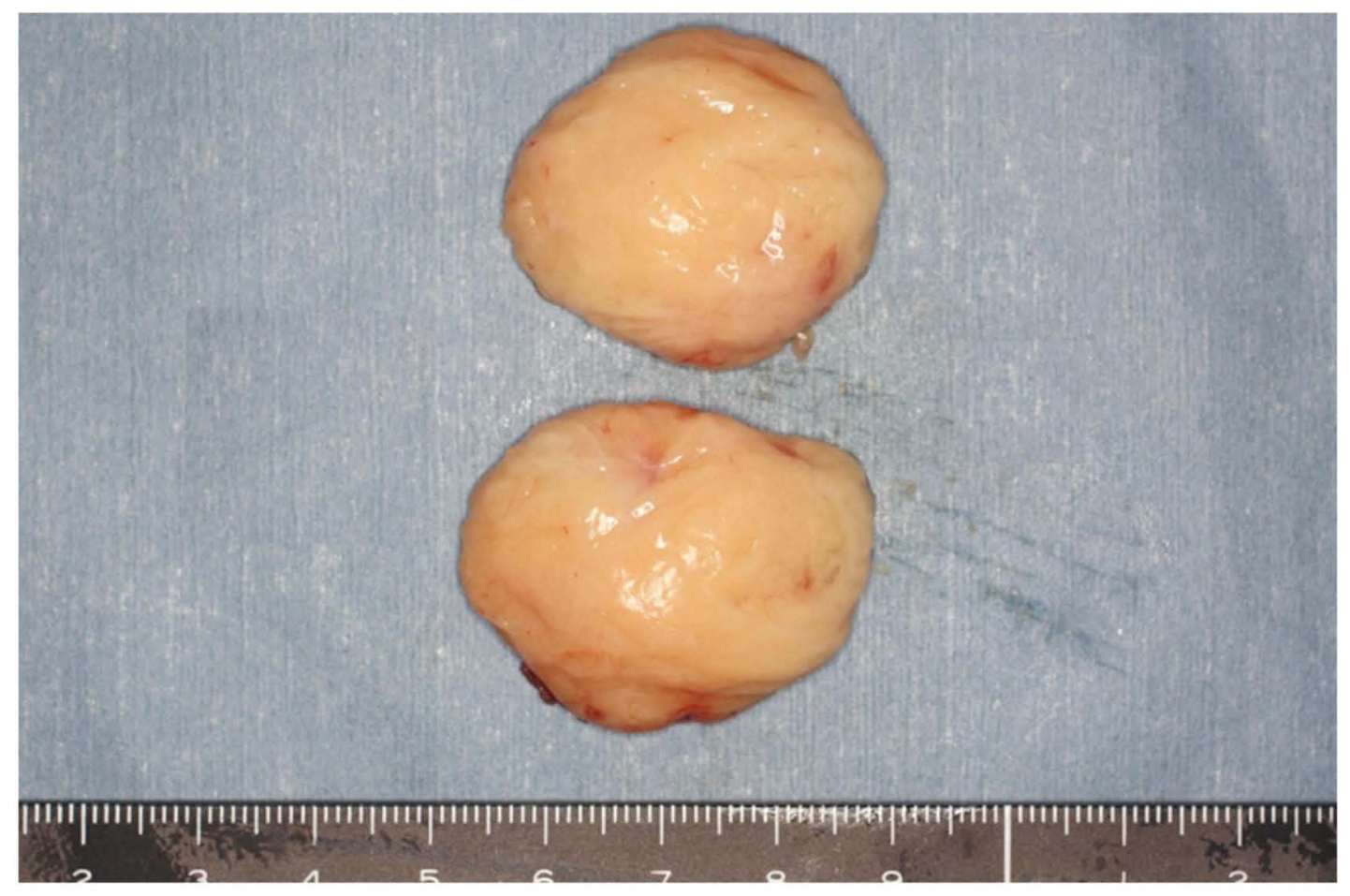


Figure 5.
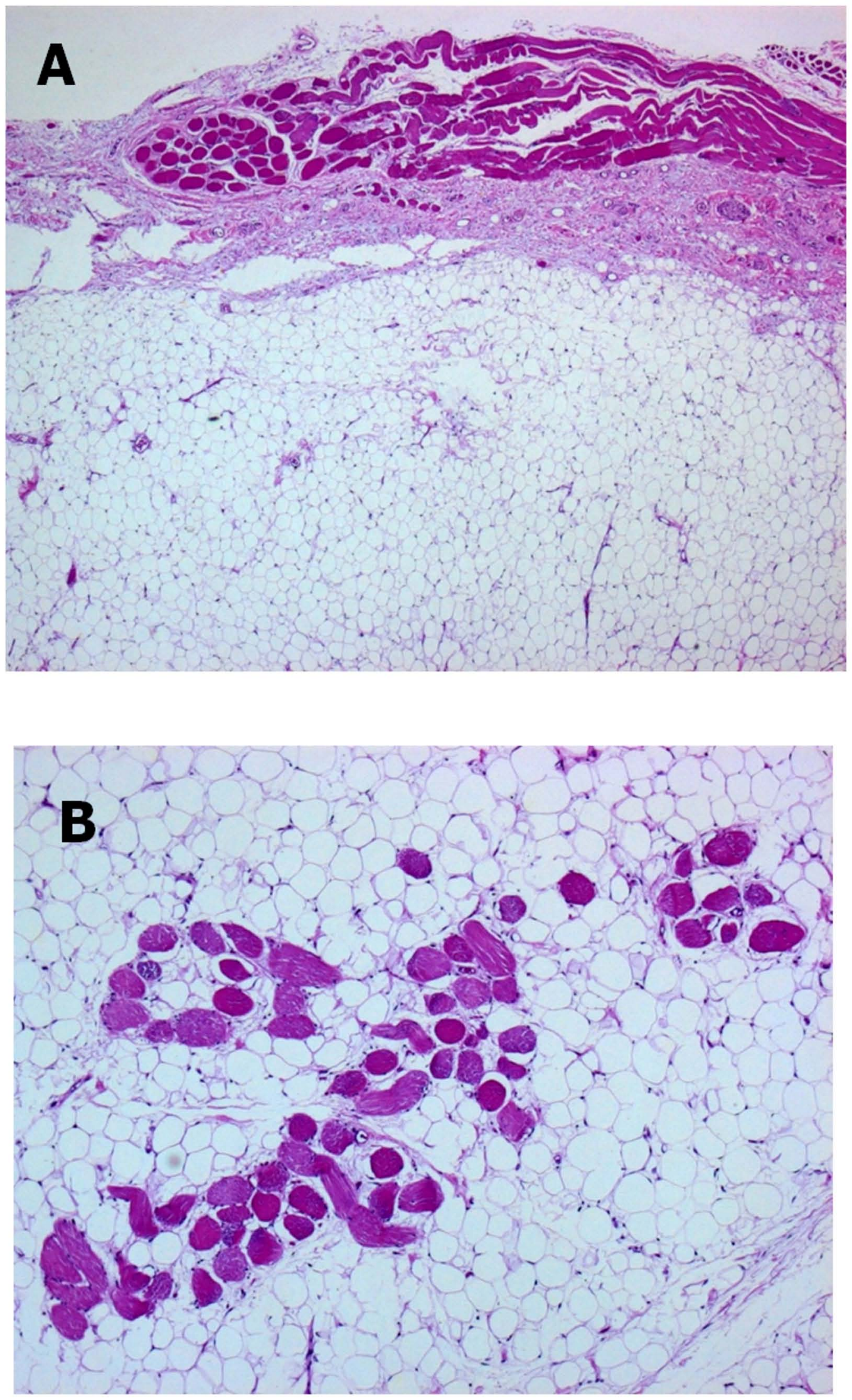